\title{
Dermatophytosis with Reference to Unani and Modern Concept: An Overview
}

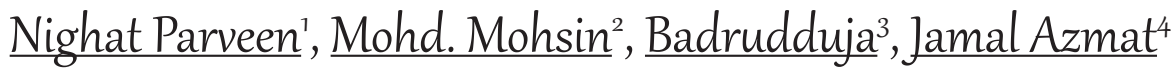 \\ ${ }^{1}$ P.G Scholar, ${ }^{3}$ Associate Professor, ${ }^{4}$ Assistant Professor, Department of Moalejat, AKTC, AMU, Aligarh, Uttar Pradesh, India. \\ ${ }^{2}$ Assistant Professor, Department of Amraz-e-Jild-wa-zahrawiya AKTC, AMU, Aligarh, Uttar Pradesh, India. \\ DOI: https://doi.org/10.24321/2319.9113.201901
}

\section{I $\quad \mathbf{N} \quad \mathbf{F} \quad \mathbf{O}$}

\section{Corresponding Author:}

Nighat Parveen, Department of Moalejat, AKTC, AMU, Aligarh, Uttar Pradesh, India.

E-mail Id:

nighatmd.amu@gmail.com

Orcid Id:

https://orcid.org/0000-0002-4685-7013

How to cite this article:

Parveen N, Mohsin M, Badrudduja et al. Dermatophytosis with Reference to Unani and Modern Concept: An Overview. J Integ Comm Health 2019; 8(1): 1-7.

Date of Submission: 2019-04-16

Date of Acceptance: 2019-06-17

\section{$\begin{array}{llllllll}\mathbf{A} & \mathbf{B} & \mathbf{S} & \mathbf{T} & \mathbf{R} & \mathbf{A} & \mathbf{C} & \mathbf{T}\end{array}$}

Dermatopytosis are superficial infections of keratinized tissue caused by organisms of three genera of fungi known as the dermatophytes. In contrast dermatomycosis represents systemic and deep fungal infections that may have prominent cutaneous and systemic manifestations. This paper demonstrates both concepts of dermatophytosis Unani and Modern. In Unani literature, it is terned as Qooba. Explaining the historical review of any disease is a very difficult thing, why did it come into existence, currently how much treatment is available for the disease and also, there is a need to assess the progression of disease whether it is progressive or curable. We always try to control the disease, So for this we review the disease from time to time and try to give the best treatment to cure the disease.

It is also interesting to note that a number of physicians have done immense work in the field of Qooba. Some of the few may be GreekoRoman, Arabs, Persian physician who has done some great amount of work with regard to Qooba.

As we may talk about the historical records and ancient literature of Qooba, It was the father of medicine,Hippocrates(377-460 BC) who first gave an ample amount of literature and right direction through his valuable humour theory.

Keywords: Unani, Modern, Qooba, Dermatophytosis, Historical Review, Unani physician

\section{Introduction}

\section{Dermatophytosis in Regards to Unani Concept}

Dermatophytosis is known with the name of Qooba in Unani litreture.

\section{Era of Unani Medicine and Unani Physician}

- Ismail jurjani $\left(12^{\text {th }}\right.$ century AD) stated in Zakheera Khwarzam Shahi, Paryun is a Persian name of qooba and in hindi it is named as Daad. He described the two main causes for the existence of qooba. One is khilte-ebad (noxious humour) and another is Quwat-e-tabiyat (corrective faculty). ${ }^{1}$

- Hakeem Akbar Arzani (17 $17^{\text {th }}$ century AD) in Tibb-e-Akbar described the Qooba as roughness of external surface of skin. It may be black or red in colour, spreading in nature and when it gets transformed into a chronic case, it sheds off like fish-like scales. ${ }^{10}$

- Ahmad Tabri (10 $10^{\text {th }}$ century AD) gave statement in Moalejat-e-Buqratiya, as that Qooba is very similar to 
urticaria, affects the external surface of skin, usually it is round in shape and it affects large surface of the body. Regarding etiopathogenesis, he said that pathogenic irritating matter escapes out from minute capillaries resulting in the formation of hyperpigmented papule which later spreads and takes large circular shape. He also mentioned that Qooba has three jins-1, jins-edamvi-2, jins-e-ratoobi- 3 and jinse saudawi. ${ }^{11}$

- $\quad$ Ali Ibn Abbas Majoosi (1930-999 AD) - He stated in his well-known book Kamil-us- sana'a, that Qooba originates from sauda which in turn originates from ehtraq-e- dam (burnt blood), he also discussed its causes, clinical presentation and treatment. ${ }^{12}$

- Rabbantabri (810-895 AD) - in his book firdausulhikamat, he mentioned that improper functioning of quwat-ehazma results into fasid blood (vicious blood) which then circulates to the whole body as a result of which itching arises. It also results in Qooba. This fasid blood contains ghilzat and baroodat. Also, the case is if hiddat comes into fasid blood and the amount of ratubat declines then it may cause the formation of dry quooba. ${ }^{13}$

- Hakeem ghulamjeelani in his book, Makhzan-e-Hikmat mentioned the detail about Qooba. He states that it is a contagious disease. When it affects head area it is termed as daussalb, in case it affects beard region, it is known as daullhayya and for nail known as daulzafeer. Small vesicles/papules appear on the surface of the skin. These vesicles combine together to form circular lesion. When these lesions burst, it may cause severe itching. ${ }^{2}$

- Hasan al Qamri (9 $9^{\text {th }}$ century AD) stated in his book Ghina Muna. The Qooba is caused by sanguine humour, which is burnt and converted into malencholic humour. When Qooba reached to muscular part it is termed as daadkaagzi. ${ }^{14}$

- Zakariya Razi (850-923 AD) stated in his book Al Havi-fitTib Qooba, its classification, treatment. He classified the Qooba into qoobaratab and qoobayabis, in addition to this he explored that local application of oil is beneficial to treat the qooba. ${ }^{15}$

- Allama Hakeem KabirUd Din explained Qooba in Tarjuma-e-Kabir (share-e-asbab), He states that Qooba is a dryness of external surface of skin, it might be red or black in colour. It is contagious in nature, caused by a particular type of madda (maddatul Qooba). If the humour develops the properties of hiddat, borquait and saudaviut due to the presence of maddatul Qooba, it might produce Qooba and may complicate it. ${ }^{16}$

\section{Definition}

- Qooba is a disease which leads roughness of skin along with this the other symptoms include-itching, scaling, dryness and sometime fish like scales sheds off from them. The color that usually appears is black or red, periphery is red and at times a yellow color fluid oozes out from it. These conditions advance as per as pathogenic substances. ${ }^{4,17,18}$

- PP Qooba causes roughness of skin surface. The upper layer of the skin starts to peel off as well as scales also sheds off from the skin. ${ }^{18}$

- It is similar to Safa'a or might be called Huzaz. But some people referred to Huzaz as the Qooba which appears on the head. ${ }^{19,20}$

- In this disease, circular patches appear on the skin along with itching. Basically, it is a kind of roughness and dryness of skin. This disease is also associated with boils in which itching appears, also a fluid ooze out from it. This disease is usually found in the hairs, head region. At times it may also occur on the beard as well. Along with it, it might affect the other regions of the body as well. ${ }^{21}$

\section{Etiology}

- If the humour develops the properties of hiddat, borquait and saudaviut due to the presence of maddatul Qooba, it might produce Qooba and may complicate it. ${ }^{16}$

- The cause of Qooba resembles to that of safa'a; that is the haad (sharp), harif (astringent) or pungent fluid which is mixed with ghaleez saudavi madda (viscous melancholic humour) more viscous than the matter of jarb (scabies). Other causes of it may be due to balghammaleh (saline phlegm) which is burnt and converted into sauda (melancholic humour). ${ }^{19}$

- The causal factors of Qooba might be a mixture of acute liquefied fluid of blood and black bile. And it may be due to melancholic humour i.e. black bile. ${ }^{18}$

- Qooba originates from raqeeq (thin) and tez (sharp) madda. ${ }^{22}$

- According to the old Unani physicians Qooba is described as roughness of skin, its color is black or red. It originates from tez (sharp) blood and also from ghaleez sauda which mixed with it. The cause of its occurrence is burned ghaleez ratubat aur balghame-shor that mixed along with tez(sharp) blood. This is found in chronic condition of qooba. ${ }^{23}$

\section{Clinical Presentation and Classification of Qooba}

As per various Unani classical text, also specified by eminent physicians as well as writers of Unani system of medicine - the clinical presentation and classification of Qooba has been explained as per the causative substances.

- Qooba leads to roughness and desquamation of skin surface, along with the shedding of skin. It seems as bars-e-aswad that did not reach up to that extent of disease. ${ }^{18}$ 
- Qooba forms clinically in accordance with its causative humours. Qooba basically a roughness of skin that also includes itching. In case of khilteratab a fluid comes out from it and in the case of khilteyabis scales appear. ${ }^{20}$

- Another variety of Qooba includes Jarabia in which itching predominates and commonly occurs in the area over scrotum. ${ }^{24}$

- It can occur at any region of the body but usually it forms in the thigh area and scrotum. Qooba leads to roughness and dryness of skin, along with continuous itching. The more the patient's scratches on it, the more the itching occurs. Owing to this the state of Qooba turns to blackish or whitish. Also, it may also lead to the formation of very small boils. From this a white coloured fluid ooze out. Qooba is also characterized by the shedding of scales from the skin. Lesions arises above the surface of the skin. At times, it is also characterized by the inflammation of the skin. The formation of boils leads to itching and burning sensation as well. ${ }^{25}$

\section{Classification of Qooba}

Different Unani physicians gave different classification of Qooba as according to their observation is given below:

- Zakaria Razi has classified it into two types: Damvi (ratab): It shows something which appears to be a reddish discoloration, followed by oozing on itching. It is produced by dam (blood), burnt and converted into sauda (black bile). It disappears easily on treatment. Saudavi (yabis): It shows a whitish discoloration. This is produced by balghamthat becomes hot and saline and converts into sauda. ${ }^{15,26,27}$

- Ibne Sina: classified the Qooba as follows. Damvi (ratab): There will be oozing but it is easily curable. Saudavi (yabis): It is produced by sauda, which is caused by ehteraq (combustion) of balghammaleh (saline balgham). Mutaqashshir: Scaling might be caused due to extreme dryness. Sometimes it may be deep seated and resembles bars-e-aswad, it may appear like slough. Ghairmutaqashshir: It does not have scale. Saeekhabees: It is spreading in nature and its cure is not easy. Waqif: It is localized and non- spreading in nature. Haad: It is acute in condition which persists for short duration and is easily curable. Raddi: It has poor prognosis and is not easily curable. ${ }^{19}$

- Rabban Tabri: has broadly classified Qooba into three types. Damvi: it is produced by kitt-e-dam or ratubate-fasidah (morbid fluid). Ratubi: It is produced due to fasad-e-ratubat and ufunat (infection). Saudwi: It is produced by akhlat which gets burned and is converted into sauda. ${ }^{11}$

- Qooba has been classified into two types on the basis of the depth of involvement in GhinaMuna. Kaghzidaad: when the disease is superficial. Bhainsyadaad: When the invasion is up to the subcutaneous tissue. ${ }^{14}$

\section{Pathogenesis of Qooba}

Tabiyat (natural power) is the main impetus or vitality that taesout the morbid matters from Aaza-e-raesa (vital organs) and henceforth drives them towards the outside of skin. This morbid matter is made up of akhlat-e-harrawalateefa (hot and thin humours) blended with Akhlate Arzia Ghaleeza (thick and gritty humours) Owing to the duplicity of matter, in the nature of Akhlat, the disease spreads in both directions. Hence, it spreads tremendously due to hiddat (intensity) and latafat (thinness) of the madda. Besides, the disease both fulminates as well as heals faster if there is predominance of akhlat-e-harra in the disease-causing material, while it develops and heals slowly if akhlate-earzia are in abundance. ${ }^{27}$

\section{Description of Dermatophytosis in Regards to Modern Concept}

Around 150 years ago marked the beginning of systemic study of dermatophytes. It was Remark who specified the mycelial characteristic of the clinical disease favus. It was Schoenlein who along with Remark supported the mentioned observation.

Gruby isolated the organism of favus in culture and in an experiment, which is performed in 1841. This study of Gruby preceded by almost four decades the work of Koch and his criteria for assessing the etiology of infection.

Raymond Sabouraud recognized the microscopic and clinical aspects of four genera of dermatophytes. His classic work is organized in a pioneered treatise, lestiegnes - 1910.

Emmons critically reviewed the taxonomic status of the dermatophytes, of which he selected only three genera: Microsporum, Trichophyton, and Epidermophyton in 1934. ${ }^{28}$

\section{Etymology}

The term tinea is frequently used to identify dermatophyte infections. This label has probably been in use for more than 1500 years as reference can be found as far back as AD 400. The Roman thought the "moth eaten" appearance of afflicted scalps resulted from the work of tinea moth worm, and so the term was born. All diseases of the scalp subsequently became known as "tinea". It appears that the British first utilized the term "ringworm" in the $16^{\text {th }}$ centuary. $^{29}$

The term tinea literally means an insect larva (clothes moth). Romans used the term tinea as they wrongly thought that insects were the cause of such infections. ${ }^{30}$

The 'ringworm' is said to date from the $15^{\text {th }}$ century and was perhaps formed because dermatophyte lesion of smooth skin is said to heal from the centre as the fungus spreads out 
from a central inoculum point. As a result of this a circular lesion or ring is formed with an enhanced eruption, also a flaky, and red periphery, and a clear centre. ${ }^{31}$

\section{Dermatophytes}

The dermatophytes represent more than 40 closely related species classified in three genera: Epidermophyton, trichophyton, and microsporum. Only a few of these species are responsible for most human infections. ${ }^{28}$

Dermatophytes are divided into three categories based on their natural habitat and usual host. Anthropophilic dermatophytes typically infect only humans. Zoophilic dermatophytes usually associated with animals but can infect humans, geophilic dermatophytes are saprophytes that thrive on keratinous materials found in the soil and also may invade keratinous tissues in animals or humans. ${ }^{32}$

\section{Clinical Description and Classification of Dermatophytosis (Qooba)}

- The clinical presentation is quite different and relies on a number of factors, including the species of fungus, which account for 3-4\% of dermatological consultations, are known as Dermatophytosis (ringworm, tinea). ${ }^{33}$

- Dermatophytosis can occur in any patient, irrespective of age or sex. ${ }^{34}$

- The archetypical lesion of a dermatophyte infection is a ringworm or tinacircinata. This is a round, scaly, lesion occurring in isolation or in clusters, usually on the trunk. The rim of each lesion is more inflamed than the centre. Typically, this form occurs in infections of the body, tinea corporis. Generally, a similar convention is adopted for describing all dermatophyte infection by using the latin term 'Tinea 'followed by the appropriate part of the body involved, also in latin. The different forms are Tinea Pedis, Tinea Corporis, Tinea Cruris, Tinea Capitis and Tinea Facei. Although the term Tinea Unguiumis still used for nail infections, many prefer the designation Onychomycosis. ${ }^{34}$

\section{Classification of Dermatophytosis (Qooba)}

Clinically, Dermatophyte infections are classified according to body regions. ${ }^{35}$

- Tinea Unguium: Tinea unguium is clinically defined as a dermatophyte infection of the nail plate. The term Onychomycosis includes all infections of the nail caused by any fungus including non-dermatophytes and yeasts. ${ }^{30}$ Dermatophyte nail infections are more common in men than women. In women affection of toenails is more common. Narrow toe shoes worn by females increases the susceptibility. ${ }^{30}$

- Tinea Manuum: Tinea which are found on the dorsal aspect of hand has all similar features of tinea corporis. Tinea of palm shows dry, diffuse, keratotic form of tinea on the soles. The dry keratotic form may be asymptomatic and the patient might be not aware of the infection, attributing the dry, thick, scaly surface to hard physical labour. Tinea of the palm is mostly seen in association with tinea pedis. The Typical pattern of involvement is one foot and two hands or of two feet one hand. ${ }^{35}$

- Tinea Barbae: Fungal infection of beard area should be considered when inflammation occurs in this area. ${ }^{35}$ In India, it is still transmitted from person to person by barber's contaminated razors. ${ }^{30}$

- Tinea Capitis: The term tineacapitis indicates dermatophyte infection of scalp. ${ }^{30}$

- Tinea Pedis or Athlete's Foot: It indicates the fungal infection of feet. It is common in men and uncommon in women. Tinea of the feet may present with the classic "ringworm" pattern but most infections are found in the toe webs or on the soles. ${ }^{35}$

- Tinea Incognito: Fungal infection treated with topical steroids often lose some of their characteristic features. Topical steroids decrease inflammation and give the false impression that the rash is improving while the fungus is flourishes secondary to cortisone induced immunologic changes. ${ }^{35}$ In tinea incognito, the margin is not raised rather it is diminished, scaling is lost and the inflammation is less to a few non-descript nodules. Often a bruise-like brownish discoloration is seen, particularly in the groins. On the face, superimposed perioral dermatitis and minor pustules may modify the picture. With chronic use, atrophy, telangiectasia and striae are probably going to be seen in the groins and axillae. In some cases, concentric rings of erythema are seen along with atrophy and talengiectasia. Although, history is very distinguishing attribute. When patient took the treatment is satisfied with the treatment in the first instance. The patient is often initially happy with the treatment. Itching and inflammatory signs curtailed.

The patient stops applying the cream and the eruption relapses with varying rapidity. Further applications bring renewed relief and the cycles are repeated. ${ }^{30}$

\section{Differential Diagnosis}

- The main differential diagnosis is intertrigo and erythrasma. ${ }^{36}$

- Candidiasis is more common in females and lesions do not have a distinct raised margin. The most characteristic clinical feature is the presence of several pustules and numerous small satellite lesions that have a typical frayed peeling edge on rupture.

- $\quad$ Pityriasis versicolor and erythrasma may be localized to the groins but are non-inflammatory and there is no central clearing.

- Intertrigo with massive bacterial colonization occurs commonly in obese individuals of either sex. It may 
show a sharp margin, but this edge is usually a simple curve where the opposed skin surfaces meet. There is an upward extension from the groin as well as down the thigh. This does not occur in tinea cruris.

- Psoriasis and mycosis fungoides may resemble to tineacruris but typical lesions in other sites can usually be found.

- Other diseases that should be excluded are contact dermatitis from clothing or deodorants, atopic dermatitis and Hailey-Hailey disease. ${ }^{30,35}$

- The feet should be examined as well and any tinea pedis or onychomycosis treated as this is usually the source of the infection. ${ }^{36}$

\section{Epidemiology}

- Currently at least 40 species of dermatophytes have been well described.22 members of the genus trichophyton, 16 in the genus microsporum and 2 species of Epidermophyton. The dermatophyte has also been grouped into three categories based on natural habitat and host preference: anthropophilic, geophilic, and zoophilic. At least 16 species affect man, but the five of major importance in the continental United States are T. rubrum, T. tonsurans, T. montagrophytes, M. canis and E. floccusum. ${ }^{29}$

- The epidemiology of fungal species differs according to age, geography, and other demographic factors. Environmental conditions and sampling methods may also affect epidemiologic data. In addition, the prevalent species tends to change overtime. ${ }^{29}$

- Tineacorporis might be transmitted by direct contact with other infected people or by infected animals through dress, furnishings, or some other lifeless fomite. Infection from other sites in the same patient e.g. reservoir infection of the feet or sometimes scalp, may be the source of tineacorporis. A tropical or subtropical climate as an in India is helpful in accelerating tineacorporis. In children the infection is most likely to be transmitted by contact with pets like cats and dogs. ${ }^{28}$

\section{Diagnosis/ Laboratory Investigations}

Qooba can be diagnosed easily through their clinical presentation. The appearance, symptoms of Qooba is very typical, easily diagnosed by its appearance.

The laboratory diagnosis of superficial and cutaneous mycosis relies on the microscopical observation of the pathogen in samples from the affected areas. This is usually followed by culture and the specific identification of the fungus. ${ }^{37}$

\section{Identification of Dermatophytes under Microscope}

Under the microscope, the dermatophytes may be identified as translucent, non-pigmented, septate mycelia or as arthrospores. Infected hairs appear as a ectothrix infection (characterized by a mosaic of round arthrospoes surrounding the hair shaft as a sheath), an endothrix infection (with arthrospores in a mosaic pattern contained within the hair shaft proper) or in a linear arrangement of vacuolated hyphal fragments in chains along the longitudinal axis of the hair shaft.

In candidiasis, budding oval yeast may be seen with pseudo hyphae. The presence of budding yeast cells would differentiate between yeast filaments (pseudo hyphae) and the true hyphae of dermatophytes. Hyphae of nondermatophyte species, especially hendersonula, are narrow, with variable width and at times have a double-countered appearance. ${ }^{30}$

- $\quad$ Artifact: perplexity may emerge from so-called mosaic artefact produced by lipid droplets appearing in a single file line between cells, particularly from specimens taken from the palm and soles. These vanish when the cells are separated further by additional heating and pressure. In spite of the fact that spores and branching hyphae are seen in superficial candida infections and tinea versicolor, and only branching hyphae are seen in dermatophyte infection. ${ }^{35}$

- Special Stains: Hyphae might be difficult to find out in a potassium hydroxide wet mount. Chlorazol fungal stain, Swartz Lamkins fungal stain, or Parker's blue ink clearly stains hyphae, rendering them visible under the power. The specialized stains are accessible from dermatologic Lab and supply. ${ }^{35}$

\section{Culture of Fungus and its Biochemical Behaviour}

It is usually not necessary to know the species of dermatophytes infecting skin in most cases because the same oral and topical agents are active against all of them.

Fungal culture is crucial for hair and nail fungal infections. The infection of scalp hair in children may begin from an animal that carries a particular species of dermatophytes. The animal can be finding out and treated or destroyed to prevent the spread of infections. Nail plate, specifically of the toenails might be infected with non-dermatophytes, such as the saprophytic mold scopulariosis, which do not show good response to treatment. Scalp hair infections in children may start from an animal that carries a typical species of dermatophyte. The recognizance is important of genus of the fungus responsible for nail pate infection before setting out on a long course of treatment. ${ }^{28,35}$

\section{Wood's Light Examination ${ }^{35}$ \\ Animal Pathogenicity Test $^{38}$ \\ Biopsy}

- $\quad$ PAS - Periodic-Acid Schiff Stain shows red hyphae 
- Methenamine silver stain shows black hyphea ${ }^{38}$

\section{Cell Surface Cytology ${ }^{38}$}

\section{Skin Test ${ }^{38}$}

\section{Dermatophytid Reaction}

- Definition: A vigorous immune response to fungi may cause manifestations distant from the site of infection. These frequently pruritic skin findings are thought to result from an interaction between the host and fungal antigens. Termed dermatophytid or "-id", they usually develop on the trunk and extremities but may involve the face, particularly the forehead and post auricular areas. Autosensitization dermatitis is another term for "id" reactions. ${ }^{29} \mathrm{~A}$ vigorous immune response to fungi may cause manifestations distant from the site of infection. These frequently pruritic skin findings are thought to result from an interaction between the host and fungal antigens. Termed dermatophytid or "-id", they usually develop on the trunk and extremities but may involve the face, particularly the forehead and post auricular areas. Autosensitization dermatitis is another term for "id" reactions. ${ }^{29}$

\section{Treatment of Qooba}

Qooba could be managed by both Unani and modern treatment along with some precaution which are helpful in prevention of recurrence of Qooba. This is other topic of discussion. So here we are not discussing it.

\section{Conclusion}

In this paper authors thoroughly studied the literature of Qooba (dermatophytosis) in both Unani and Modern. However, the presentation of Qooba in both Unani and modern literatures are same, but their etiology of the disease are different. The perception of Unani physician about clinical presentation of Qooba according to their clinical experienced almost identical as per the opinion of modern physician. While exploring the Unani literature we got different Unani formulations for treatment of Qooba. They are very beneficial in Qooba with no reactions and most of them are still not manufactured or not be in use. So people should beware about Unani preprations. Now, there is a need of exploring Unani formulations, its efficacies, and prove how profitable it is. In Unani Pathy, many substitutes are available in topical as well as in systemic forms for the treatment of Qooba. Unani treatment can be used safely (without side effects) in place of allopathic treatment.

\section{Acknowledgement}

Authors are appreciatively grateful to all, Paper is composed in an easy way because of them. Thanks to the Librarians of A.M.U, Aligarh who provided us material and to writers whose papers are referred to for the references to formed this paper.
1. Synonyms $s^{1-4}$

2. Persian: Paryun, Baryoon, Daryoon, Karyoon

3. Hindi: Daad, Dadru

4. English: Dermatophytosis, Favus, Ferion, Tinea, Ringworm, Superficial fungal infection ${ }^{5-9}$

\section{Conflict of Interest: None}

\section{References}

1. Jurjani I. Zakheera Khwarzam Shahi. Vol. 7 (Urdu translation by Khan $\mathrm{HH}$ ). Idara Kitabus Shifa, New Delhi. 2010; 24-26.

2. Jeelani G. Makhzan-e-Hikmat. Vol. 2. Faisal Publication, Deoband. 2009; 1031-1032.

3. Arzani A. Mizanut Tib. $4^{\text {th }}$ edition. Hyderabad Dakan, 1952.

4. Khan MA. Akseer Azam. Vol. 4. Matba Nizami, Kanpur. 1289 (AH), 436-439.

5. Patil D. A one-year cross sectional study of clinical type and etiological agent of superficial dermatophytosis at KLE'S Hospital and MRC, Belgaum. JNMC, Belgaum. 2008.

6. Ledingham JGG, Warrell DA. Concise Oxford Text book of Medicine. Oxford University Press, New York. 2000, 117119-21.

7. Larry Jameson J, Fauci AS, Kasper DI et al. Harrison's Principles of Internal Medicine. Vol. 2. $19^{\text {th }}$ edition. McGraw-Hill Education, 2015; 349-350.

8. Siddarth SN. API Text book of Medicine. $7^{\text {th }}$ edi. The Association of Physicians of India, Mumbai. 2003; 1304-1305.

9. The Macmillan Family Encyclopaedia. Vol. 8. Macmillan Press Ltd., London. 1995; 369.

10. Akbar A. Tibbi-e-Akbar (Urdu translation by Husain M). Idara Kitabusshifa, New Delhi.

11. Tabri AM. Molejat-e-Buqratiya (Urdu Translation by CCRUM). Vol. 2. Ministry of Health and Family Welfare, New Delhi. 1997; 211-213.

12. Majusi AIA. Kamilus Sana'a (Urdu translation) by Kanturi GH. Vol. 2. Idara Kitabusshifa, New Delhi. 2010; 252.

13. Tabri AR. Firdausul Hikmat (Urdu translation by Avval shah Sambhali). Faisal Publications, Deoband. 2002; 294-295.

14. Qamri AMH. Ghina Muna. PNM; YNM, 392-397.

15. Razi AMBZ. Alhavi fit Tib (Urdu translation by Jafri sab and Siddiqui). Vol. 23. Saba Publication, Aligarh. 1994; 46-52.

16. Kabeeruddin H. Tarjuma-e-Kabir (Urdu translation of sharah-e-Asbabwaalamat). Vol. 3. $1^{\text {st }}$ edition. Ajaz Publication House, New Delhi. 2007; 240-242.

17. Khan MA. Ramooze Azam. Vol. 2. Delhi Printing Press, Delhi. 1335 AH, 374-376.

18. Jamaluddin. Aqsaraee. Vol. 1. Munshi Nawal Kishore, YNM. 478-479.

19. IbnSina AA. Al Qanoon fit Tib. Vol. 4. $1^{\text {st }}$ edi. Darul Kutub 
Al IImiyah, Beirut. 1999; 415-417.

20. Antaki DZ. Tazkiratul Ulul Albab. Part 3. $3^{\text {rd }}$ edi. AlMatba Al Azharia, Misr. 1924, 129.

21. Hijazi MR. Kanz-ul-Ilaj. S. K. Basheer \& Sons Pub., Lahore. YNM, 479-480.

22. Chandpuri K. Mojaz-ul-Qanoon. Sprinter South Anarkali, Delhi. 2000; 457.

23. Qurshi MH. Jame-ul-Hikmat. Idara Kitabus Hifa, 2011. 997-998.

24. Shamshuddin M. Makhzan-e-Sulaimani. Matba Nizami Munshi Nawal Kishore, 1308 AH, 659-660.

25. Ajmal K. Hazique. Beesween Sadi Book Depot, N.S Marg; New Delhi. YNM, 546-548.

26. Razi AMBM. Kitabul Mansoori (Urdu translation by CCRUM). Ministry of Health and Family Welfare, New Delhi. 1991; 205-206.

27. Razi Z. Kitabul Fakhir Fit Tib (Arabic translation by CCRUM). Vol. 1. Ministry of Health and Family Welfare, New Delhi. 2005; 40-42.

28. Freedberg Irvin M. Fitzpatrick's Dermatology in General Medicine. Vol. 2. $5^{\text {th }}$ edi. McGraw-Hill, 1999. 2327, 2339, 2327-2353.

29. Ronald and Lawrence. Pediatric Dermatology. $3^{\text {rd }}$ edi. 2003, pp.1093, 1094, 1097, 1099, 1101.

30. Valia RG, Valia AR. Text Book and Atlas of Dermatology. Vol. 1. $2^{\text {nd }}$ edi. Bhalani Publishing House, Mumbai. 2001, 215-18, 222-232.

31. Liz J. Dermatophytes-the skin eaters. Mycologist 2003; 17: 147-149.

32. Barnhill RL. Textbook of Dermatopathology. McGrawHill Companies. 1998; 409-413.

33. Weedon D. Skin Pathology. $2^{\text {nd }}$ edition. Elsevier Science Limited. 2002; 660-662.

34. Noble WC. The Skin Microflora and Microbial skin Diseases. Cambridge University Press. 1993, 232-234, 239, 244-45.

35. Habif TP. Clinical Dermatology, A colour Guide to Diagnose and Therapy. $4^{\text {th }}$ edi. Mosby London, New York. 2004. pp.227, 409, 413, 426, 417, 420, 409, 417, 434, 410-412, 426.

36. White Gray M. Disease of the Skin, Color Atlas and Text. Moaby New York, Philadelphia; St. Louis, Sydney, Toronto. 2000, 360.

37. Yasmeen K. Text Book of Dermatology. $1^{\text {st }}$ edition. Vol. 1. Royal Falcon Enterprises. 2007; 161-65, 167-69, 180-81.

38. Haldar B. Diagnosis and treatment of skin disorders. Skin Institute Publication, Calcutta. 1988, 76, 77, 81, 82,85 . 